\title{
Article \\ Compact Design of Annular-Microstrip-Fed mmW Antenna Arrays
}

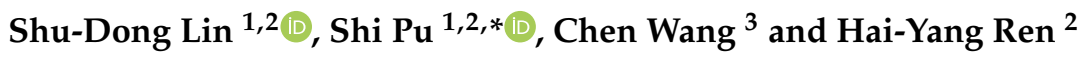 \\ 1 Hubei Key Laboratory of Roadway Bridge and Structure Engineering, Wuhan University of Technology, \\ Wuhan 430070, China; shudonglin@whut.edu.cn \\ 2 Department of Physical Science and Technology, School of Science, Wuhan University of Technology, \\ Wuhan 430070, China; renhaiyang@whut.edu.cn \\ 3 Altair Engineering Software (Shanghai) Co., Ltd., Shanghai 200070, China; chen.wang@altair.com.cn \\ * Correspondence: sidpu@whut.edu.cn
}

check for updates

Citation: Lin, S.-D.; Pu, S.; Wang, C.; Ren, H.-Y. Compact Design of Annular-Microstrip-Fed mmW Antenna Arrays. Sensors 2021, 21 3695. https://doi.org/10.3390/ s21113695

Academic Editors: Youchung Chung and Cynthia M. Furse

Received: 28 February 2021

Accepted: 21 May 2021

Published: 26 May 2021

Publisher's Note: MDPI stays neutral with regard to jurisdictional claims in published maps and institutional affiliations.

Copyright: (c) 2021 by the authors. Licensee MDPI, Basel, Switzerland. This article is an open access article distributed under the terms and conditions of the Creative Commons Attribution (CC BY) license (https:// creativecommons.org/licenses/by/ $4.0 /)$.

\begin{abstract}
In this paper, a series of four novel microstrip antenna array designs based on different annular-microstrip feeding lines at $60-\mathrm{GHz}$ millimeter wave $(\mathrm{mmW})$ band are proposed, aiming at the potential usage of the $\mathrm{mmW}$ coverage antenna with multi-directional property. As the feeding network, the annular contour microstrip lines are employed to connect the patch units so as to form a more compact array. Our first design is to use an outer contour annular microstrip line to connect four-direction linear arrays composed of $1 \times 3$ rectangular patches, thus the gain of $8.4 \mathrm{dBi}$ and bandwidth of over $300 \mathrm{MHz}$ are obtained. Our second design is to apply the two-direction pitchfork-shaped array each made up of two same linear arrays as the above, therefore the gain of $9.65 \mathrm{dBi}$ and bandwidth of around $250 \mathrm{MHz}$ are achieved. Our third design is to employ dual (inner and outer contour) annular-microstrip feeding lines to interconnect the above four-direction linear arrays, while our fourth design is to bring bridged annular-microstrip feeding lines, both of which can realize the goal of multi-directional radiation characteristic and higher gain of over $10 \mathrm{dBi}$.
\end{abstract}

Keywords: microstrip antenna; array; mmW; feeding line; multi-direction

\section{Introduction}

Millimeter wave $(\mathrm{mmW})$ frequency band is shown to have much potential usage not only for the near future wireless communication system like 5G NR FR2, but also for the other upcoming signal coverage system based on the protocols of 802.11ad (Wi-Gig) or $802.11 \mathrm{bd}$. According to previous research, different types of $\mathrm{mmW}$ antenna structures working at $\mathrm{mmW}$ frequency bands with novel structures or designing methods have been proposed before. The substrate integrated waveguide (SIW) technology, dual-element arrays, and extension structures have been used in designing the directional horn antenna working at 5G mmW bands [1]. Defected ground structure (DGS) [2], $1 \times 4$ antipodal Vivaldi antenna (AVA) array structure [3], H-shaped and slot-loaded patch with a shorting pin structure [4] have also been proposed in patch antennas working at $5 \mathrm{G} \mathrm{mmW}$ bands such as $28 \mathrm{GHz}$. Besides, the rectangular dielectric resonator antenna with circular patch obtains the radiation efficiency at $26 \mathrm{GHz}$ and can be applied in higher frequency of $5 \mathrm{G}$ $\mathrm{mmW}$ from $24.25 \mathrm{GHz}$ to $27.5 \mathrm{GHz}$ with the optimization of the rectangular slot and cross slot [5]. New structures such as the superposition of identical metallic layers based on metasurface can attain the high gain of $27 \mathrm{dBi}$ at $28 \mathrm{GHz}$ [6]. In the frequency band of $60 \mathrm{GHz}$, some antennas are combined with IC technology. For example, the low-loss Low Temperature Co-Fired Ceramic (LTCC) has been utilized in wide-band $60 \mathrm{GHz}$ chip antenna and it enables better radiation effectiveness compared with the patch antenna integrated into PCB [7]. A kind of virtual annular antenna has been proposed for use on CMOS IC technology with the achievement of a radiation efficiency of $90 \%$ and a gain of $1.43 \mathrm{dBi}$ at about $60 \mathrm{GHz}$ [8]. What is more, different kinds of antennas have been shown 
such as the inverted-F antenna and quasi-Yagi patch antenna which are working at $\mathrm{mmW}$ bands [9]. There are also plenty of designs based on microstrip antenna arrays such as the modified $2 \times 2$-element and $2 \times 2$-slot element $60 \mathrm{GHz}$ planar array antenna [10,11], microstrip grid array antennas [12,13], microstrip antenna with comb line shape [14], and a microstrip patch antenna array which excites the frequency selective surface (FSS) with two elements [15], etc. Some of the above-mentioned designs are focusing on achieving the high gain. The microstrip grid array antennas can obtain the $14 \mathrm{dBi}$-highest-gain at $60 \mathrm{GHz}$ and the impedance bandwidth from $57 \mathrm{GHz}$ to $66 \mathrm{GHz}$ [13]. The microstrip antenna with comb line shape can attain the high gain of $20.3 \mathrm{dBi}$ [14]. Some other methods such as loading Artificial Magnetic Conductor (AMC), constructing composite metamaterial, and isotropic meta-surfaces have been proposed to improve gain [16-18]. However, in this paper, our goal is to achieve more homogeneous coverage with more isotropic radiation instead of high gain, while the articles which are focusing on isotropic or multi-directional radiation property are few.

Facing the main issues of obtaining the characteristics of miniaturization, planarity, and integration of antennas and aiming at the potential applications in $\mathrm{mmW}$ indoor or outdoor propagation scenarios, a series of four novel microstrip antenna array designs based on different annular-microstrip feeding lines at around $60 \mathrm{GHz}$ are proposed in this paper. In the process of designing the antenna structure to be more compact, the annular microstrip feeding lines which can connect patch units and various compact structures are proposed as the feeding network. On this basis, we improve the surface current distribution of all arrays to be more uniform in order to obtain the multi-directional radiation characteristic under linear polarization mode. Some of our preliminary studies have been already reported in the patents [19-21] and conference papers [22,23]. In Section 2, the principle of our design and the two basic designs based on annular microstrip line with different forms of patch arrays will be proposed. In Section 2.2, the fabrication and experimental results of the first basic structure will be shown, which is the verification of our designs. In Section 3, the latter two designs would show the methods of acquiring multi-directional characteristics, with four linear arrays using dual annular feeding method and central feeding mode based on the requirements of uniform surface current distribution.

\section{Theory and Analysis of Annular Microstrip Feeding Design}

\subsection{Outer-Annular Microstrip-Fed Antenna Array}

To achieve the compact feature, the outer annular microstrip line has been analyzed and designed by us. No matter how many branches there are in each structure, we follow the principle that the length of the outer annular microstrip line between every two branches should be the integral multiple of the half-wavelength of the central frequency. For instance, as shown in Figure 1a, the annular microstrip line is divided into four parts. So, the length of each part of annular microstrip line should be designed as above.

If this requirement has been met, the quantity of the branches can be designed as $2 \sim 6$ at designer's option. One point that needs to be assured is that the input impedance of each branch should be equal to $50 \Omega$ after being calculated in parallel. Besides, the initial values of the width of the microstrip lines should generally meet the following computational formulas [24]:

$$
\begin{gathered}
m=\frac{Z_{\mathrm{c}} \sqrt{2\left(\sqrt{\varepsilon_{\mathrm{r}}+1}\right)}}{120}+\frac{\varepsilon_{\mathrm{r}}-1}{\varepsilon_{\mathrm{r}}+1}\left(0.2258+\frac{0.1208}{\varepsilon_{\mathrm{r}}}\right) \\
\frac{d_{\mathrm{n}}}{q}=\frac{8 e^{m}}{e^{2 m}-2}
\end{gathered}
$$

where $Z_{\mathrm{c}}$ is the impedance of the microstrip line, $\varepsilon_{\mathrm{r}}$ is the relative dielectric coefficient, $d_{n}(n=0$ or $n=1)$ is the width of the microstrip line, and $q$ is the thickness of the microstrip line and $m$ is the interim parameter. 
(a)

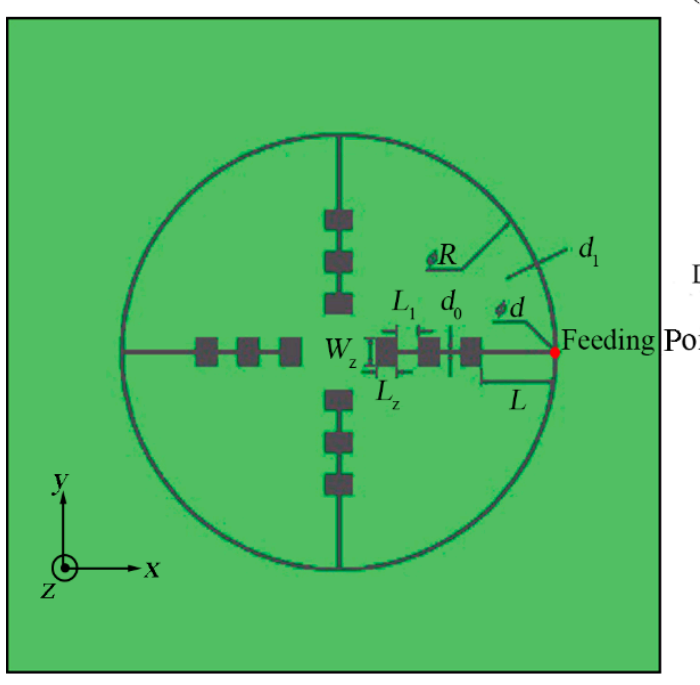

(b)

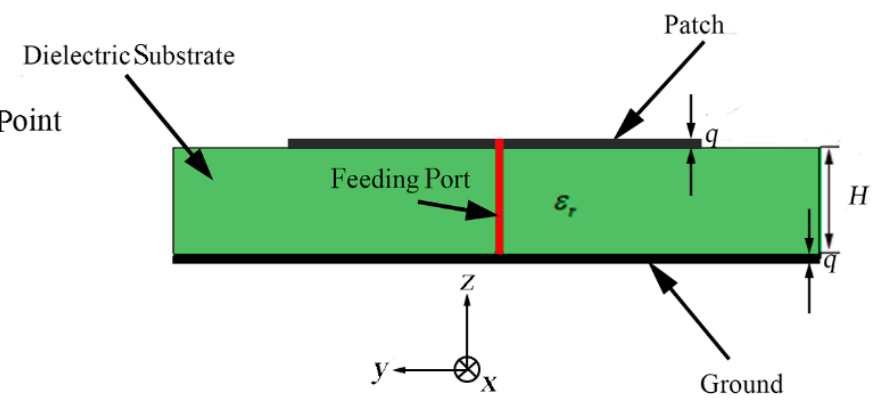

Figure 1. Outer-annular microstrip-fed antenna array, (a) top view, (b) side view.

Besides, we choose rectangular patches as the radiation elements in our design. When setting the initial values of the patches, we follow the following computational formulas:

$$
\begin{gathered}
\varepsilon_{\mathrm{e}}=\frac{\varepsilon_{\mathrm{r}}+1}{2}+\frac{\varepsilon_{\mathrm{r}}-1}{2}\left(1+12 \frac{H}{L_{\mathrm{z}}}\right)^{-\frac{1}{2}} \\
\Delta L=0.412 H \frac{\left(\varepsilon_{\mathrm{e}}+0.3\right)\left(\frac{L_{\mathrm{z}}}{H}+0.264\right)}{\left(\varepsilon_{\mathrm{e}}-0.258\right)\left(\frac{L_{\mathrm{z}}}{H}+0.8\right)} \\
f_{\mathrm{r}}=\frac{c}{2\left(W_{\mathrm{z}}+2 \Delta L\right) \sqrt{\varepsilon_{\mathrm{e}}}}
\end{gathered}
$$

where $\varepsilon_{\mathrm{e}}$ is the effective relative dielectric coefficient of the substrate, $H$ is the thickness of the dielectric substrate, $\Delta L$ is the length of equivalent radiation gap, $f_{r}$ is the resonant frequency, $L_{\mathrm{z}}$ is the length of each patch, $W_{\mathrm{Z}}$ is the width of each patch, and $c$ is the speed of light in vacuum.

The four antenna structures in this paper are flexible and easy to adjust the bandwidth by changing parameters such as the thickness of the dielectric substrate, which means that our designs have good robustness and can meet the general bandwidth requirements of different application scenes. However, employing the equivalent formulas (1)-(5) are not enough to guide us to design the annular-microstrip-fed $\mathrm{mmW}$ antenna arrays we need. Hence, all simulations are using a commercial Method of Moments (MoM) solver (Altair Feko) in this paper, which is one of the famous full-wave numerical methods for 3D electromagnetic field computation.

As shown in Figure 1, we propose the outer-annular microstrip-fed antenna array as the basic structure. We use an outer contour annular microstrip line to connect four directional linear arrays with $1 \times 3$ rectangular patches. We set the white point as the feeding point which is at the center of the right-hand outer annular microstrip line. The punched hole with the diameter of $d$ shown in the Figure 1 is designed for the further experimental soldering with the coaxial probe.

All the patches, microstrip line and the ground of bottom layer are applied by silver with the thickness of $q=0.006 \mathrm{~mm}$. Besides, the whole antenna array is etched on both surfaces of the two sides of the aluminum oxide dielectric substrate with the relative dielectric coefficient of $\varepsilon_{\mathrm{r}}=9.8$ and thickness of $H=0.12 \mathrm{~mm}$ [25]. In the simulation, the dielectric substrate is set as infinite plane. Besides, the four identical shaped patch array branches are all designed for implementing the input impedance of $200 \Omega$ in order 
to match the requirement of input impedance value $50 \Omega$ at the coaxial probe feed port from the observed antenna terminal. The final width of each microstrip line depends on formulas (1) and (2) and the final length of each microstrip line depends on the simulation results. Each patch is designed as working in the central frequency of $60 \mathrm{GHz}$ according to formulas (3)-(5), with the length of $1.05 \mathrm{~mm}$ and the width of $0.78 \mathrm{~mm}$.

After analyzing and calculating, we set the inner diameter of the outer annular microstrip line as $R=16.50 \mathrm{~mm}$ and the width of the outer annular microstrip line as $d_{1}=0.110 \mathrm{~mm}$. Other detailed parameters of this structure have been demonstrated in Table 1. The meanings of these parameters are shown in Figure 1a.

Table 1. Parameters of outer-annular microstrip-fed antenna array.

\begin{tabular}{cccc}
\hline Parameter & Value $(\mathbf{m m})$ & Parameter & Value (mm) \\
\hline$W_{\mathrm{z}}$ & 1.050 & $L_{1}$ & 0.830 \\
$L_{\mathrm{z}}$ & 0.780 & $d_{1}$ & 0.110 \\
$d_{0}$ & 0.130 & $R$ & 16.500 \\
$L$ & 2.830 & $d$ & 0.800 \\
$q$ & 0.006 & $H$ & 0.12 \\
\hline
\end{tabular}

The gain and the reflection coefficient of the outer-annular microstrip-fed antenna array have been shown in Figure 2.

(a)

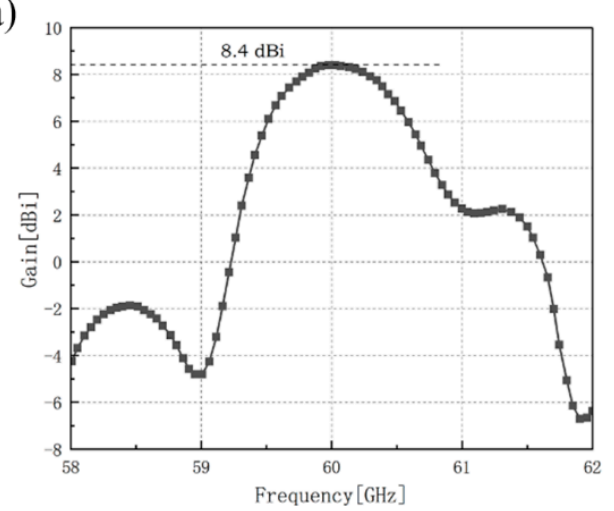

(b)

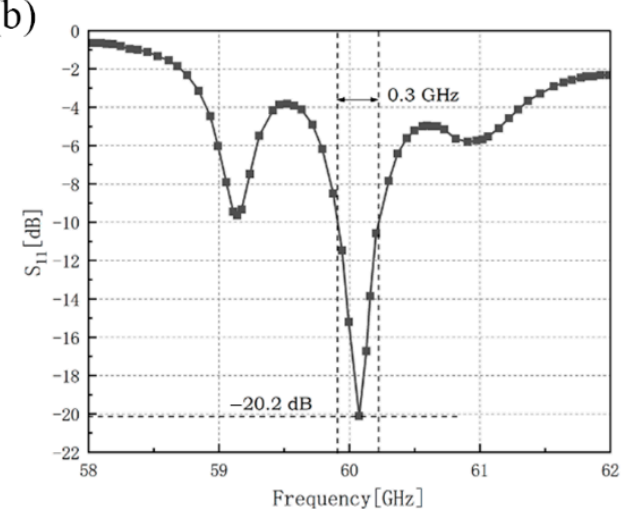

Figure 2. Simulation results of outer-annular microstrip-fed antenna array, (a) gain of this antenna array, (b) reflection coefficient of this antenna array.

The maximum gain of the outer-annular microstrip-fed antenna array is $8.4 \mathrm{dBi}$ at $60.0 \mathrm{GHz}$ and the minimum reflection coefficient of it is $-20.2 \mathrm{~dB}$ at $60.1 \mathrm{GHz}$ with the impedance bandwidth of $0.3 \mathrm{GHz}$.

Moduli and the detailed vector plots of the instantaneous surface current distribution of the outer-annular microstrip-fed antenna array are shown in Figure 3.

After analyzing the surface current distribution in Figure 3, we find that the edge feeding mode will generally cause the currents on the side feeding units too little. This is the reason why the radiation range of antenna is relatively narrow and non-uniform. What is more, looking at the detailed vector plot of the surface current on patches, it is shown that patches on the parallel main feeding units are the same in phase while patches on the side feeding units are in opposition of phase. The opposition of phase of the opposite branches will influence the gain and the aperture efficiency of the antenna array to some extent. We also show the $x-z$ plane, $y-z$ plane, and $x-y$ plane of the radiation pattern of the outer-annular microstrip-fed antenna array in Figure 4. The pure line represents the co-polarization, whereas the dashed line represents the cross-polarization pattern. 


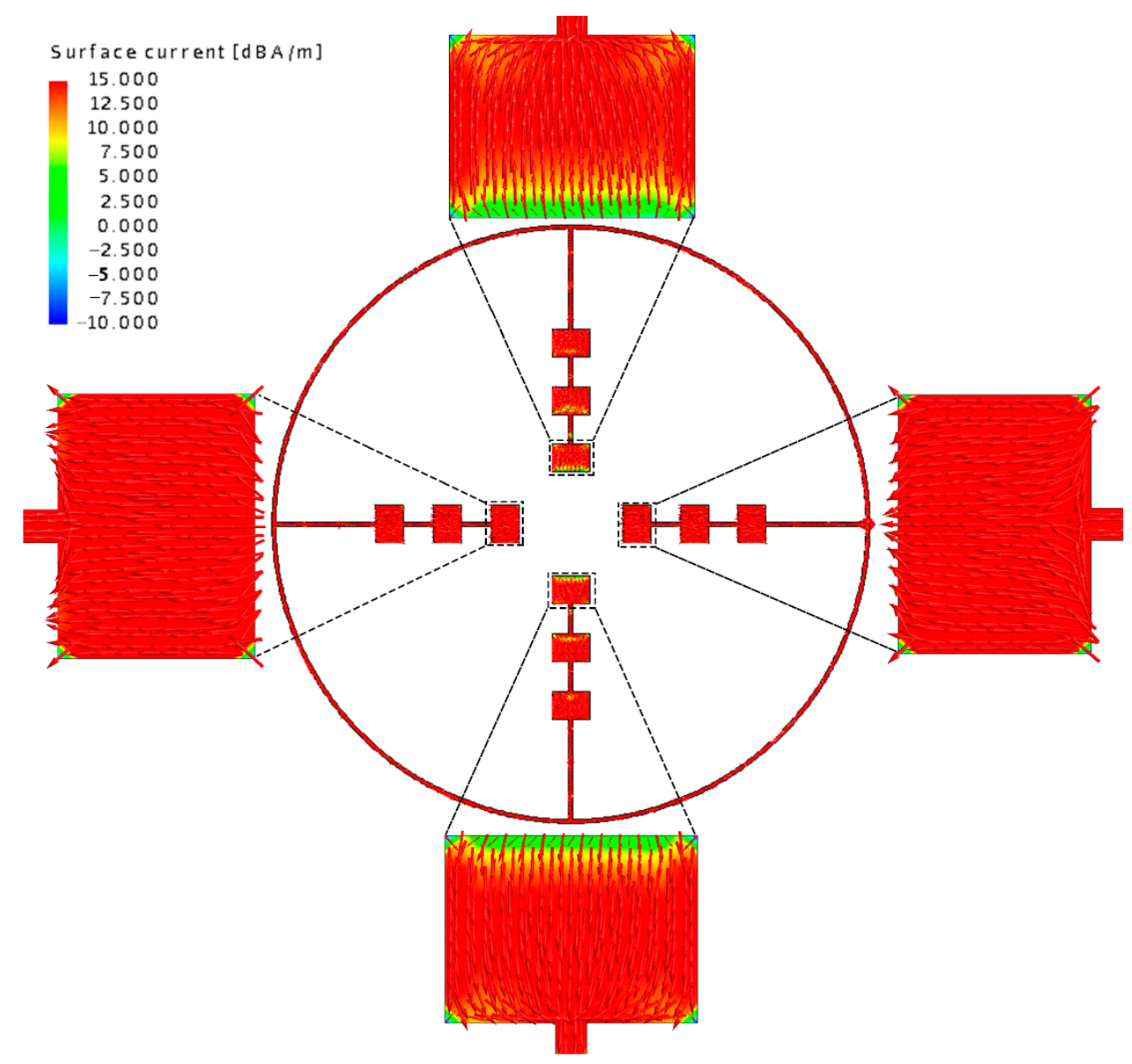

Figure 3. Moduli and the detailed vector plot of the instantaneous current distribution of the outer-annular microstrip-fed antenna array at around $60 \mathrm{GHz}$.

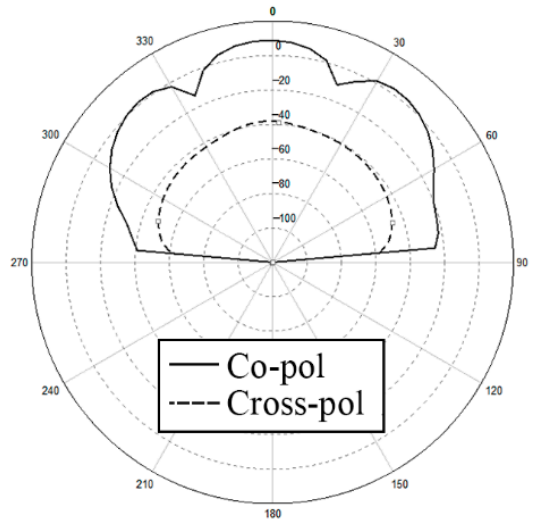

(a)

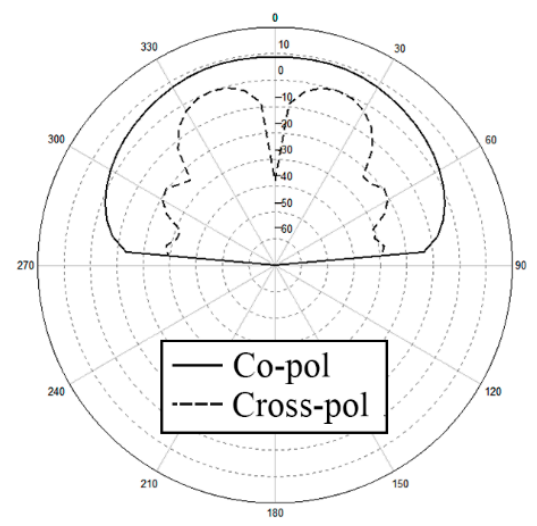

(b)

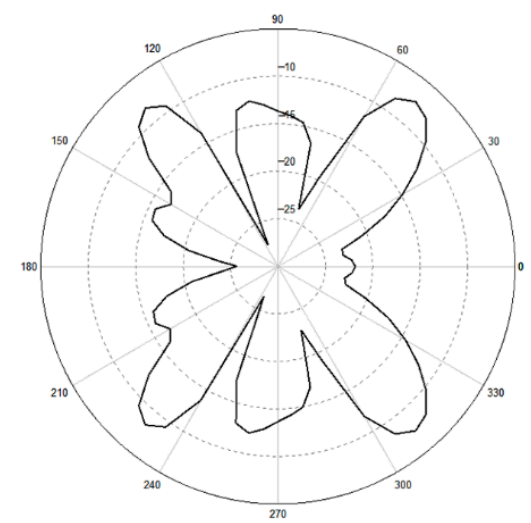

(c)

Figure 4. Radiation pattern of the outer-annular microstrip-fed antenna array (a) $x-z$ plane, (b) $y-z$ plane, (c) $x-y$ plane.

2.2. Verification of the Basic Structure of Outer-Annular Microstrip-Fed Antenna Array

2.2.1. Comparation of Simulation Result and Experimental Result

In the verification, we choose to make the first basic structure into manufactured object. The metal patch was printed on an aluminum oxide substrate with $\varepsilon_{\mathrm{r}}=9.8$ and $H=0.12 \mathrm{~mm}$, as depicted in Figure 1. The patch is made of silver with the thickness of $q=0.006 \mathrm{~mm}$. The antenna adopts the coaxial feeding port, and the feeding point is located as Figure 1 shown. The antenna is connected to the vector network analyzer by using a $1 \mathrm{~mm}$ connector from Southwest Microwave, Inc. The manufactured object is 
shown in Figure 5. While hermetically packaging, the coaxial connector is attached to the threaded mounting holes where a glass bead is positioned mid-way between them. The $1 \mathrm{~mm}$ connector is shown in Figure 6 and the manufactured object after soldering is shown in Figure 7. The connector is soldered on the bottom side of the ground plane by flange as shown in Figure $7 \mathrm{~b}$.

(a)

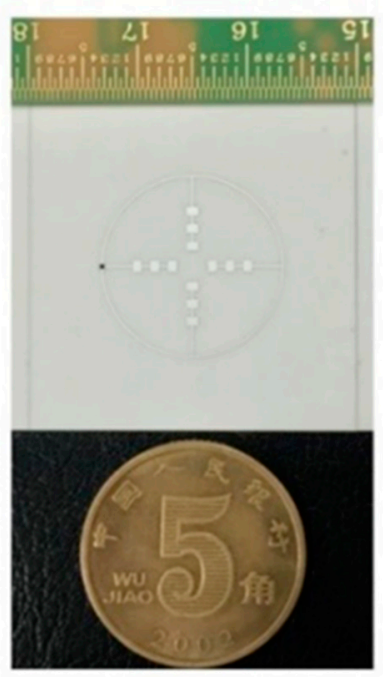

(b)

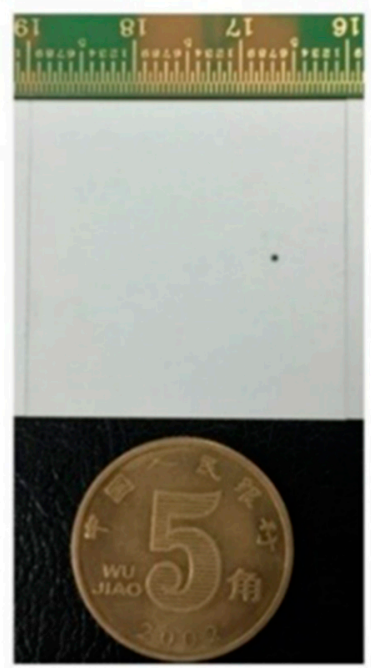

(c)
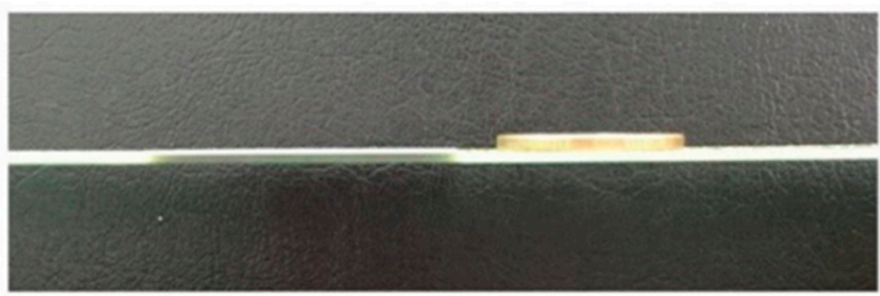

Figure 5. Photo of the manufactured object of the first structure, (a) the top view, (b) the bottom view, (c) the side view.

(a)

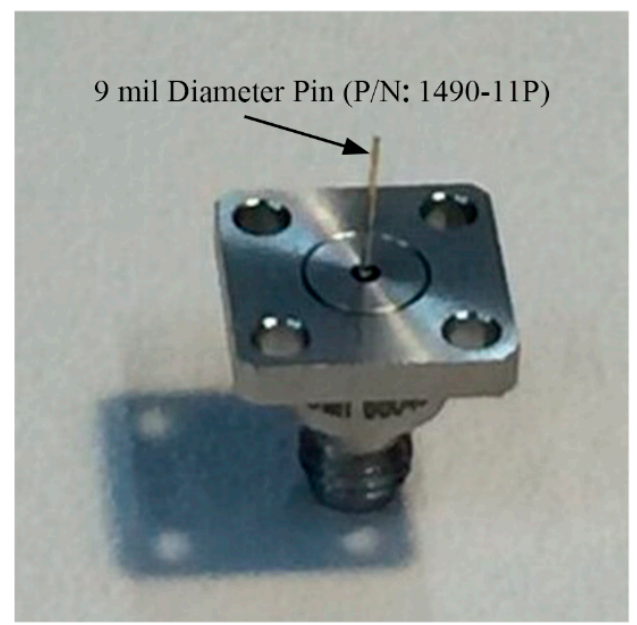

(b)

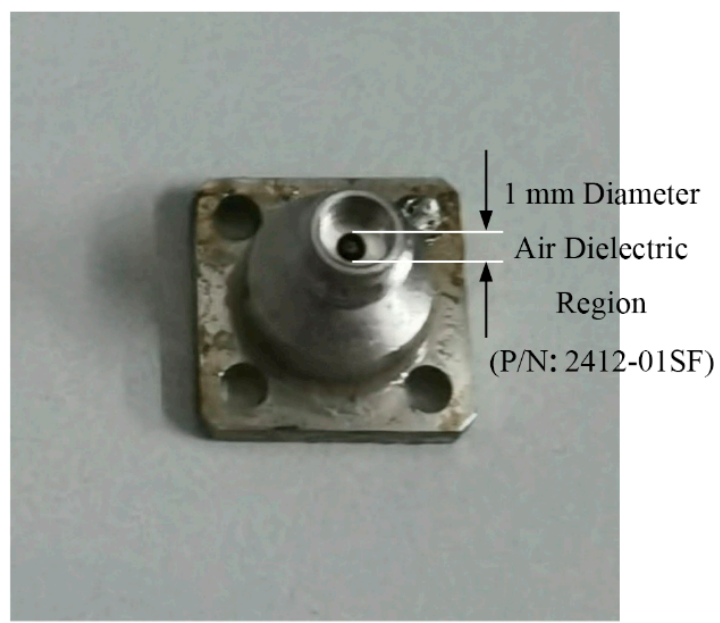

Figure 6. Photo of the $1 \mathrm{~mm}$ connector, (a) 3D view from pin to thread, (b) 3D view from thread to pin. 
(a)

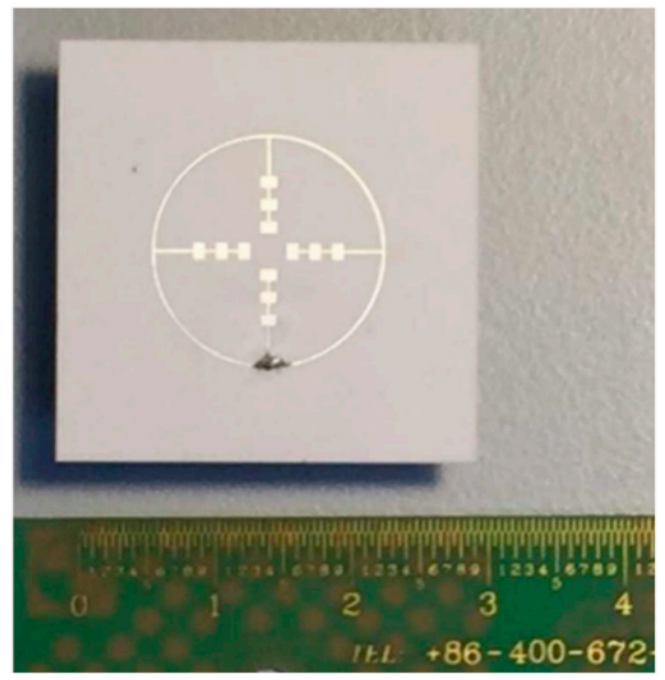

(b)

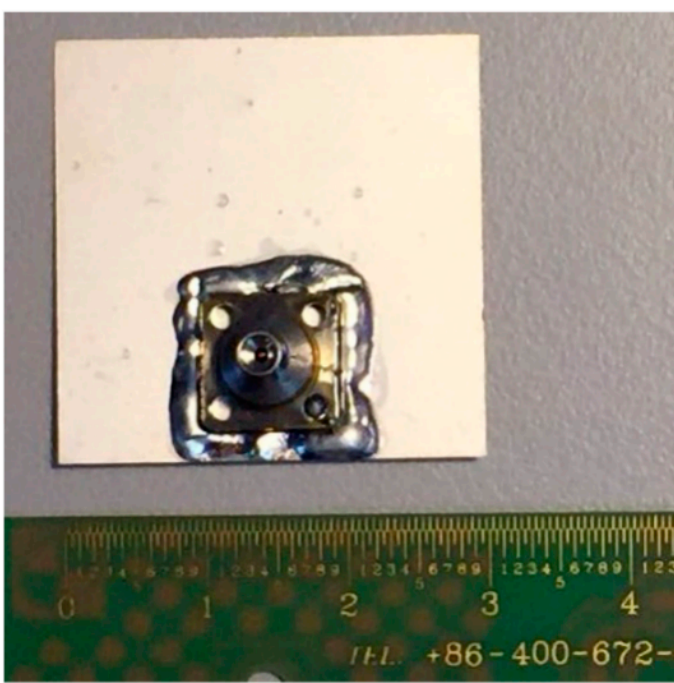

Figure 7. Photo of the manufactured object after being soldered, (a) the top view, (b) the bottom view.

The experimental work was carried out in Rohde \& Schwarz ${ }^{\circledR}$ open laboratory in Shanghai with the ZVA110 vector network analyzer $(10 \mathrm{MHz}-110 \mathrm{GHz})$. The results are shown in Figure 8. The resonant frequency of the antenna is $60.65 \mathrm{GHz}$ and the minimum reflection coefficient of it is $-14.55 \mathrm{~dB}$ at $60.65 \mathrm{GHz}$ with the bandwidth of $0.54 \mathrm{GHz}$. Because the antenna structure in this paper is easily affected by the $1 \mathrm{~mm}$ connector structure, the antenna's resonant frequency experimental result has shifted to a certain extent with the similar entire trend compared with the simulation result.

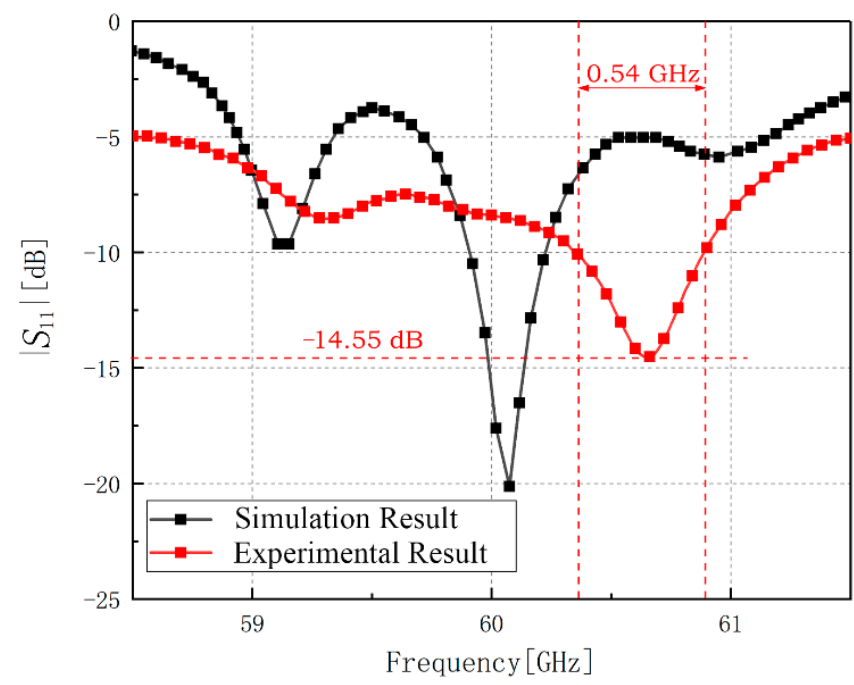

Figure 8. Simulation result and experimental result of the reflection coefficient of the first structure.

\subsubsection{Add-on Analysis with a Connector}

In the simulation, we set the feeding port as the wire port which is more consistent with the actual application scenario. However, in order to achieve a more precise experimental result, the coaxial feeding method is used in the experiment. So, the possible cause of the shift of the result is the $1 \mathrm{~mm}$ connector. Aiming at this point, we still use Altair FEKO to analyze the characteristics of the antenna under the coaxial feeding method. The verification model with coaxial feeding method is shown in Figure 9. We set the material of the coaxial feeding conductors as perfect electric conductor. The coaxial feeding port is composed of internal cylinder block and outer cylindrical surface. The internal diameter is $D_{1}=0.005 \mathrm{~mm}$ and the outer diameter is $D_{2}=0.0146 \mathrm{~mm}$. The coaxial feeding method 
penetrates the dielectric substrate to feed the antenna array. It is worth mentioning that the coaxial feeding method with edge port in the simulation is just a kind of approximation of the $1 \mathrm{~mm}$ connector because of the high complexity of the $1 \mathrm{~mm}$ connector. The comparation of the simulation result, experimental result, and the simulation result with coaxial feeding method is shown in Figure 10.

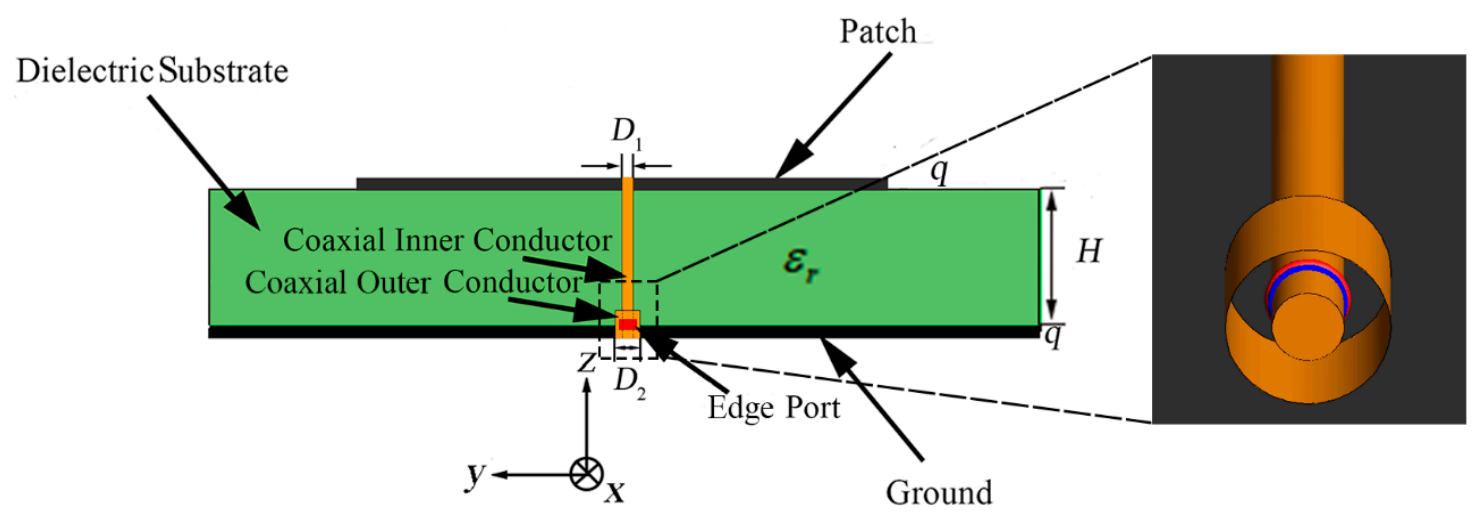

Figure 9. The side view and local detail of the verification model with coaxial feeding method.

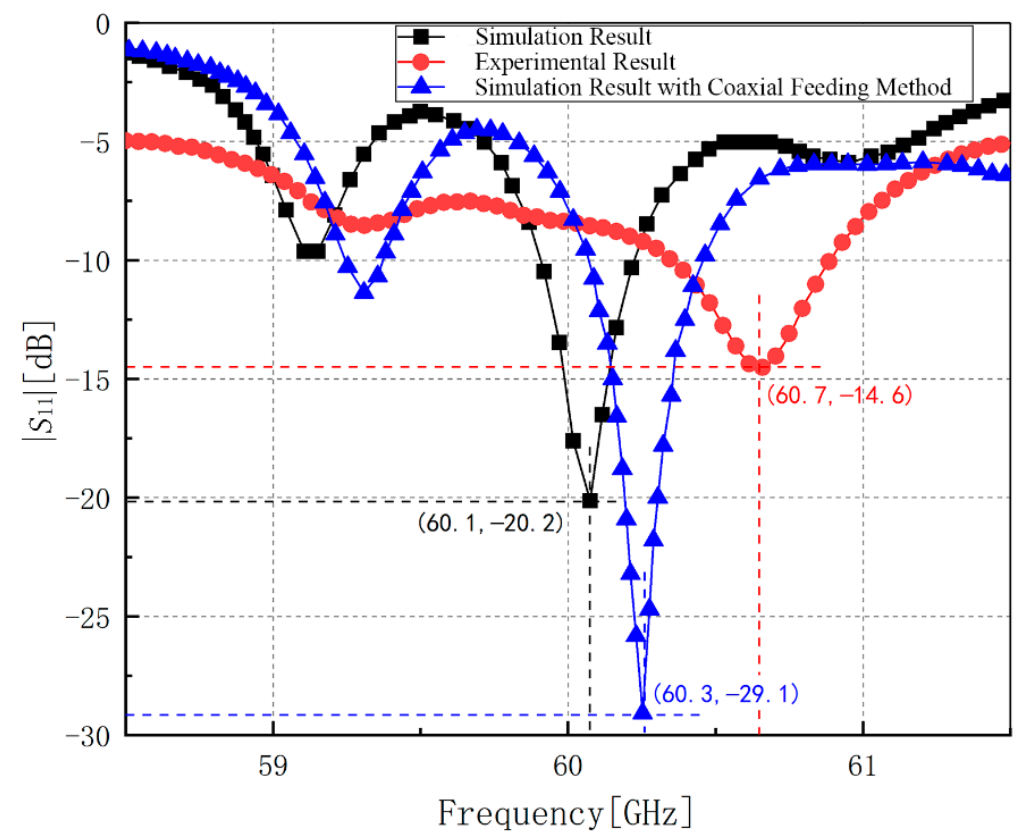

Figure 10. Comparation of the simulation result, experimental result, and the simulation result with coaxial feeding method.

As shown in Figure 10, after using the coaxial feeding method with edge port to replace the original wire feeding port, the resonance frequency moves $0.2 \mathrm{GHz}$ to the right which has a similar trend as the experimental result. Additionally, the bandwidth appears to overlap with the experimental result, which means the results are almost coincident. It is necessary to state that various probable factors will influence the experimental result and enlarge the difference of resonant frequency in the experimental process, especially in such a high frequency band, such as the poor soldering, the change of the resistance because of the soldering tin, and the size of the dielectric substrate. Besides, the resonant frequency of our experimental result is still in the $60-\mathrm{GHz}$ frequency band and the shift is far less than the possible deviation because of the manufacture craft and test process which means it makes no sense in focusing on such deviation in practical application. Thus, our experimental result can be verified. 


\subsection{Two-Direction Pitchfork-Shaped Microstrip Antenna Array}

As shown in Figure 11, we propose the microstrip antenna array consists of outer annular microstrip line and two pitchfork-shaped array branches as the second design. Each pitchfork-shaped branch is composed by two linear arrays each with $1 \times 3$ rectangular patches. This design is similar to the basic design, but the difference is that we use pitchforkshaped feeding mode inside the outer annular microstrip line. Initially, the structure was still designed as four array branches. However, the upper and lower branches will influence the radiation characteristics because of the opposition of phase of the two side feeding units. So, we finally adopt two opposite array branches.

(a)

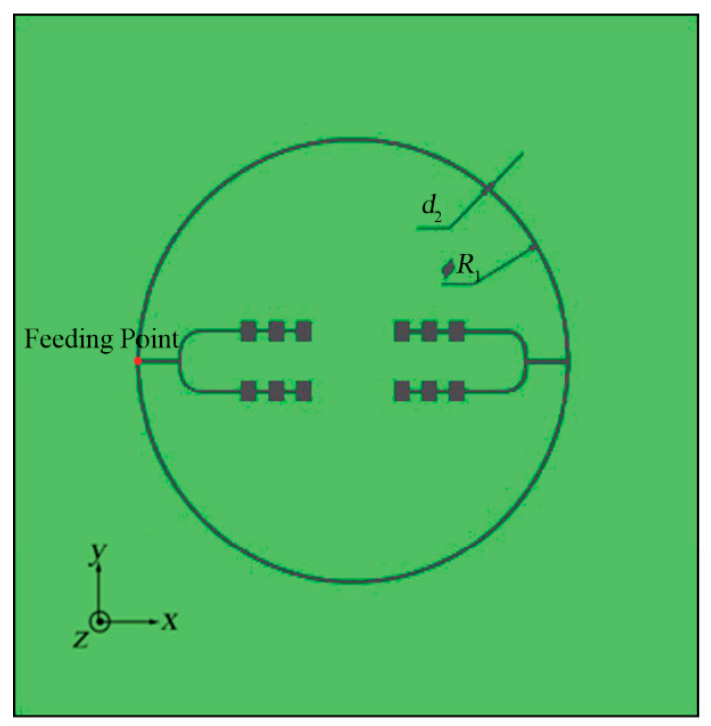

(c)

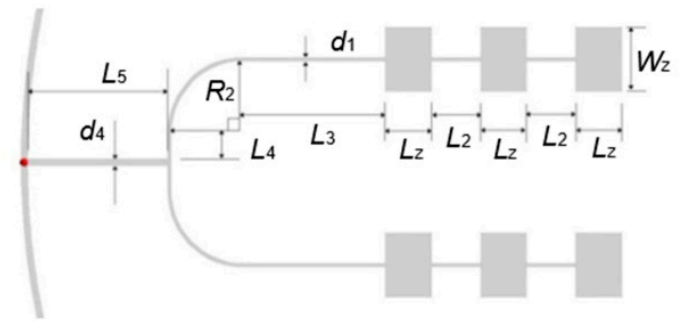

(b)

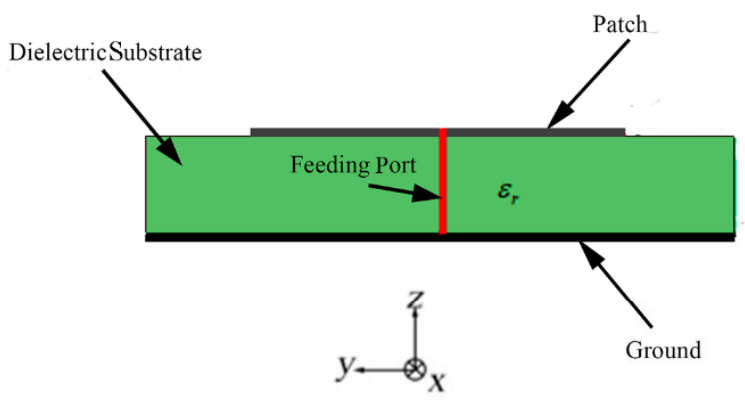

(d)

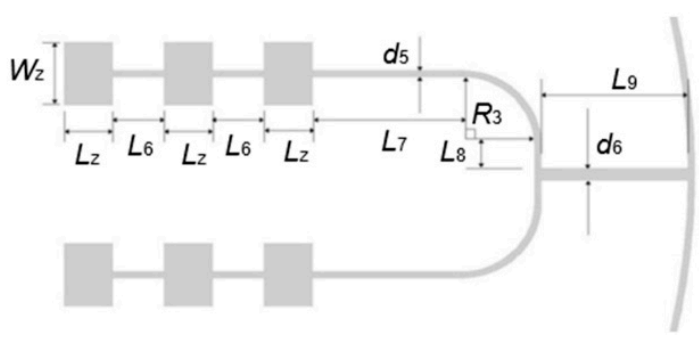

Figure 11. Two-direction pitchfork-shaped microstrip antenna array, (a) top view, (b) side view, (c) the left-side pitchforkshaped branch (input impedance of $150 \Omega$ ), (d) the right-side pitchfork-shaped branch (input impedance of $75 \Omega$ ).

We set the red point as the feeding point which is at the center of the left-hand outer annular microstrip line in order to feed the two asymmetrical radiating pitchfork-shaped branches. The two pitchfork-shaped patch array branches consist of twelve rectangular patches in total.

The materials and thicknesses of patches, microstrip line, and the mental ground of bottom layer are the same as normal annular-shaped microstrip antenna array. Besides, in order to meet the requirement of the input impedance value $50 \Omega$ at the coaxial probe feed port from the observed antenna terminal, the two pitchfork-shaped branches need to be designed for implementing the input impedance of $75 \Omega$ and $150 \Omega$, respectively.

We set the inner diameter of the outer annular microstrip line as $R_{1}=25.870 \mathrm{~mm}$ and the width of the outer annular microstrip line as $d_{2}=0.110 \mathrm{~mm}$, as shown in Figure 9 . Other detailed parameters of the structure have been demonstrated in Table 2. The meanings of these parameters are shown in Figure 9. 
Table 2. Parameters of two-side pitchfork-shaped branches.

\begin{tabular}{cccc}
\hline Parameter & Value $(\mathbf{m m})$ & Parameter & Value (mm) \\
\hline$L_{\mathrm{z}}$ & 0.780 & $L_{5}, L_{9}$ & 2.445 \\
$L_{2}, L_{6}$ & 0.860 & $W_{\mathrm{z}}$ & 1.050 \\
$L_{3}, L_{7}$ & 2.490 & $d_{2}$ & 0.11 \\
$L_{4}$ & 0.445 & $d_{3}, d_{5}$ & 0.055 \\
$L_{8}$ & 0.390 & $d_{4}$ & 0.110 \\
$R_{1}$ & 25.870 & $d_{6}$ & 0.220 \\
$R_{2}$ & 1.243 & $R_{3}$ & 1.215 \\
\hline
\end{tabular}

The gain and the reflection coefficient of the microstrip antenna array consists of outer annular microstrip line and two pitchfork-shaped array branches have been shown in Figure 12.

(a)

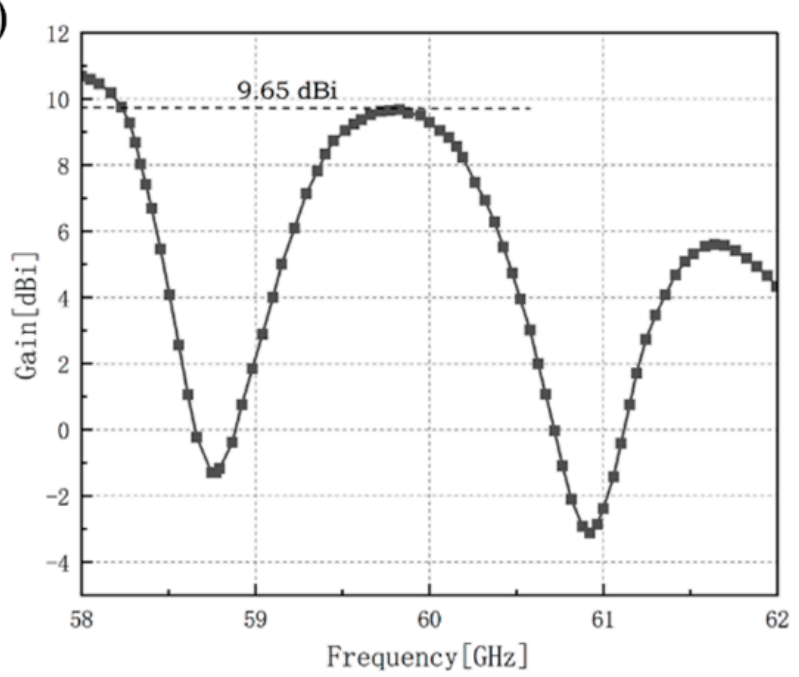

(b)

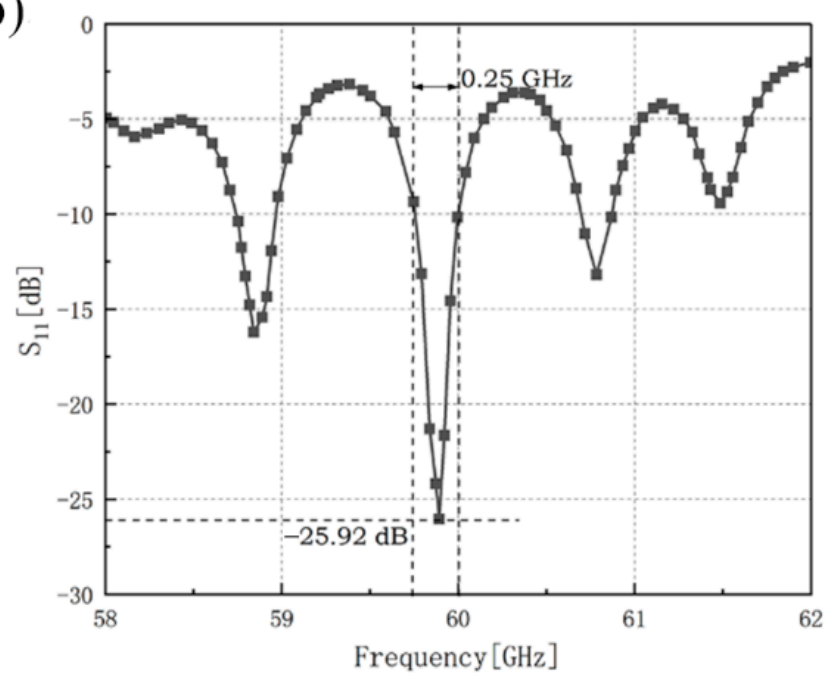

Figure 12. Simulation results of two-directional pitchfork-shaped microstrip antenna array, (a) gain of this antenna array,

(b) reflection coefficient of this antenna array.

The maximum gain of two-direction pitchfork-shaped microstrip antenna array is $9.65 \mathrm{dBi}$ at $59.8 \mathrm{GHz}$ and the minimum reflection coefficient of it is $-25.92 \mathrm{~dB}$ at $59.9 \mathrm{GHz}$ with the impedance bandwidth of $0.25 \mathrm{GHz}$. Our designs reach a good impedance matching.

Moduli and the detailed vector plots of the instantaneous surface current distribution of two-direction pitchfork-shaped microstrip antenna array are shown in Figure 13. Without the side feeding units, the only opposite units are the same in phase which relatively increase the gain and the aperture efficiency of the antenna array compared with the first structure. The asymmetric design will impact the current on the branch with larger input impendence relatively little. This will also mean that antenna cannot obtain uniform radiation on more directions.

Besides, we show the $x-z$ plane, $y-z$ plane, and $x-y$ plane of the radiation pattern of pitchfork-shaped microstrip antenna array in Figure 14. 


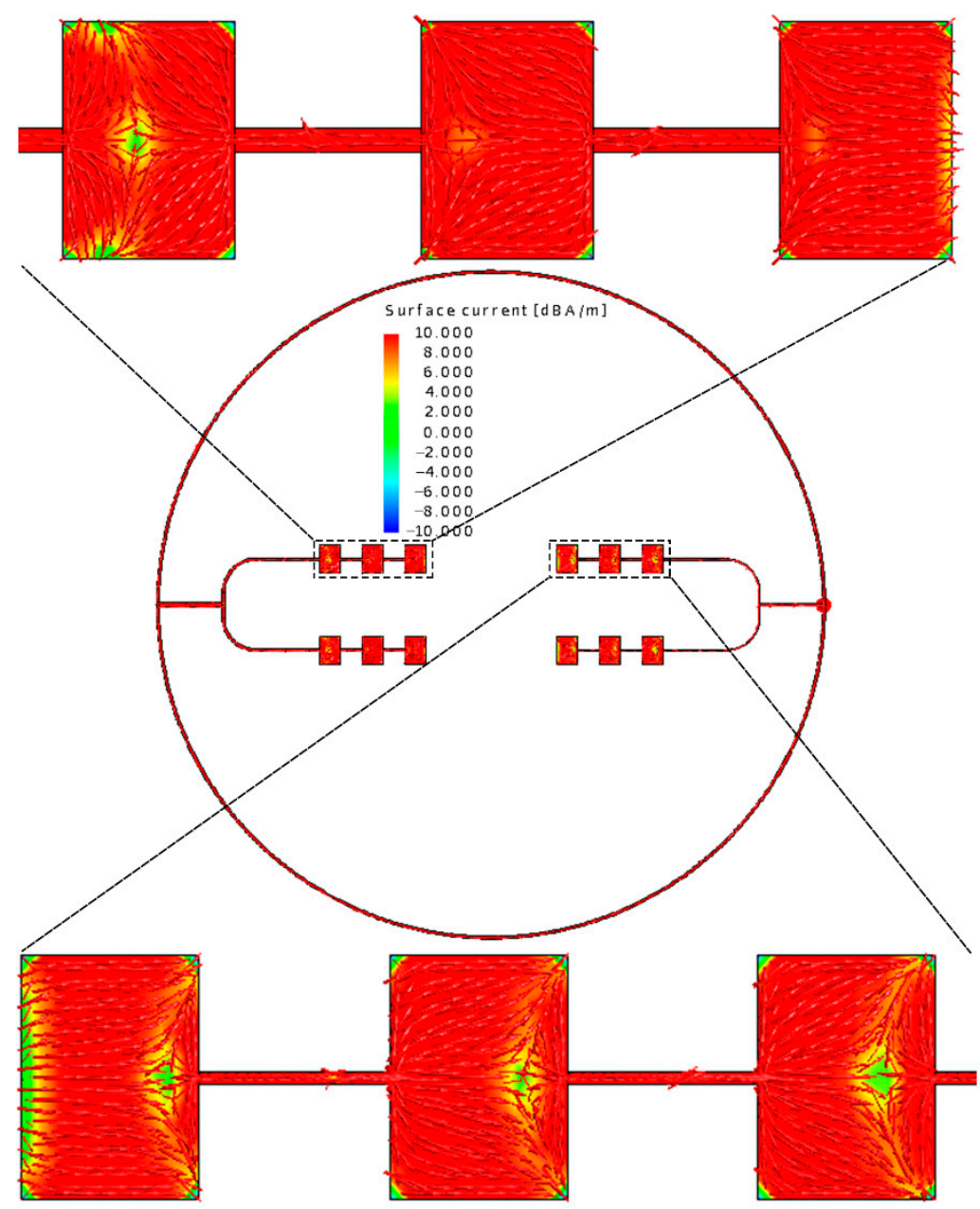

Figure 13. Moduli and the detailed vector plot of the instantaneous current distribution of twodirection pitchfork-shaped microstrip antenna array at around $60 \mathrm{GHz}$.

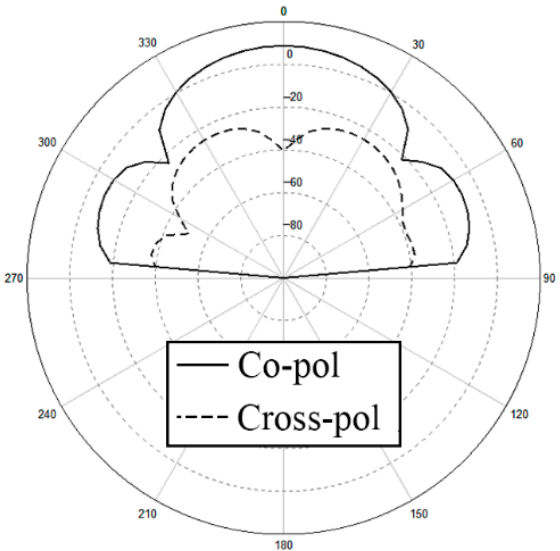

(a)

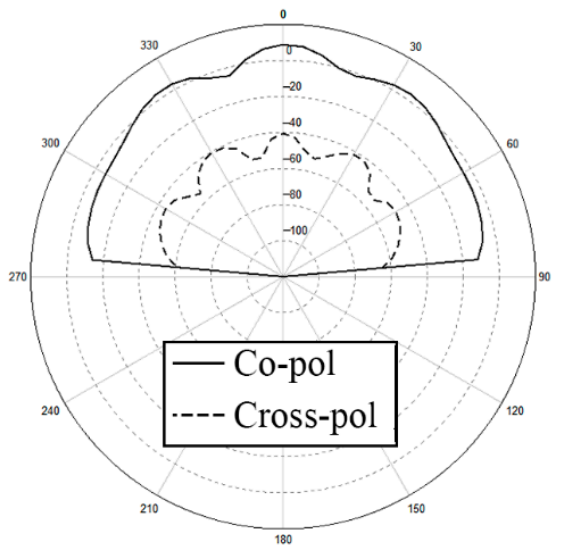

(b)

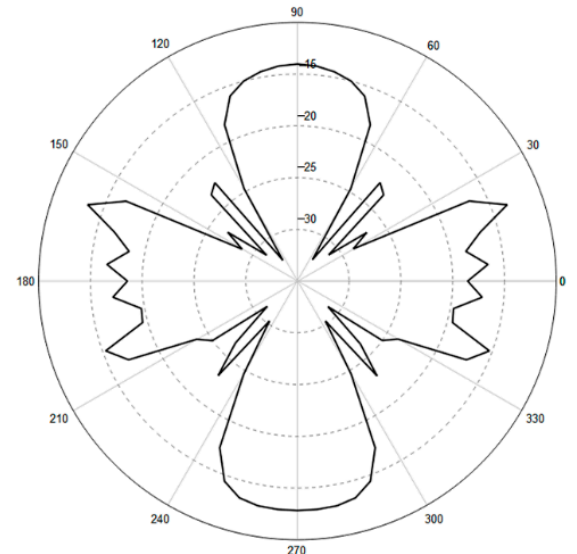

(c)

Figure 14. Radiation pattern of two-direction pitchfork-shaped microstrip antenna array (a) $x-z$ plane, (b) $y-z$ plane, (c) $x-y$ plane.

\section{Improvement on Multi-Directional Design}

In this part, two solutions of acquiring the characteristic of more uniform multidirectional radiation on the basis of outer annular microstrip line will be shown. More uniform multi-directional radiation does not mean better radiation characteristic but would probably be used in different usage scenarios. 


\subsection{Dual Annular-Microstrip-Fed Antenna Array}

This structure is shown in Figure 15 as the third design. The main purpose of this design is obtaining the characteristic of more uniform multi-direction radiation. In the first two designs, we can find that the edge feeding mode will generally cause the current on the non-main feeding units which are not connected with the feeding point is too small, which leads to the problem of inhomogeneous circumferential radiation. Aiming at solving this disadvantage, our researchers try to optimize the surface current distribution of the arrays to be uniform. In this case, in order to attain the characteristic of multi-directional radiation, it is also important to maintain more directional linear arrays. Our thought is to achieve this goal under the same edge feeding mode. Initially, we attempt to use the simple cruciform microstrip lines to interconnect the four linear arrays. However, because the length of microstrip lines in this situation is hard to be designed precisely enough, the impedance matching cannot achieve a favorable consequence. So, compared with pitchfork-shaped microstrip antenna array, in this design, we employ dual (inner and outer contour) annular microstrip lines to interconnect the four directional linear arrays with $1 \times 3$ rectangular patches. The inner annular microstrip line will connect the other end of the four branches which effectively make the current distribution on the four branches tend to be uniform. The design method of the inner annular microstrip line is the same as it of the outer annular microstrip line which means the length of the inner annular microstrip line between every two branches should also be the integral multiple of the half-wavelength of the central frequency. What is more, in order to ensure normal current feeding of the inner annular microstrip line, the width of the inner annular microstrip line has to be the same as other adjacent microstrip lines.

(a)

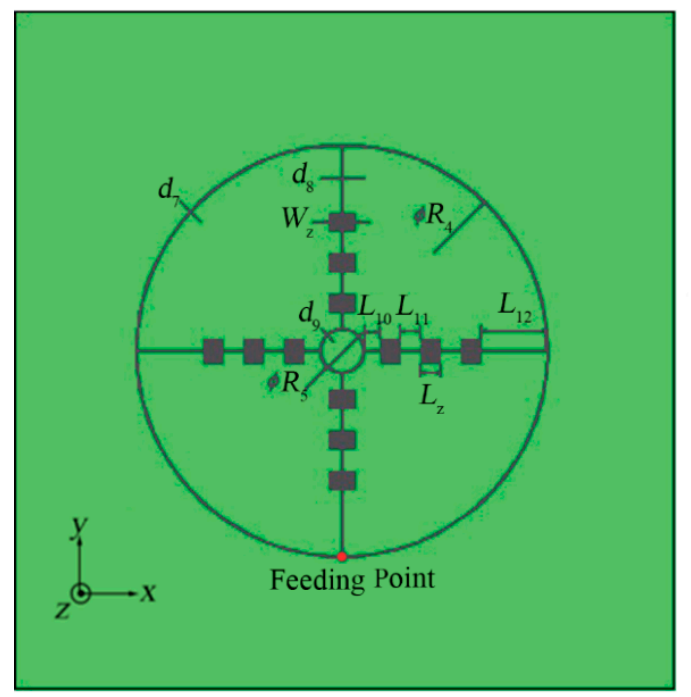

(b)

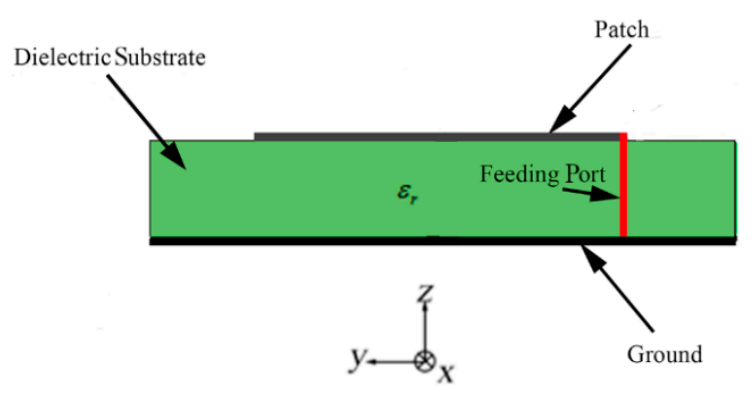

Figure 15. The dual-annular microstrip-fed antenna array, (a) top view, (b) side view.

After analyzing and optimizing, we determine the values of the parameters which are shown in Table 3. The meanings of the parameters are shown in Figure 15.

Table 3. Parameters of dual-annular microstrip-fed antenna array.

\begin{tabular}{cccccccccc}
\hline Parameter & $d_{\mathbf{7}}, d_{\mathbf{9}}$ & $\boldsymbol{d}_{\mathbf{8}}$ & $\boldsymbol{W}_{\mathbf{z}}$ & $\boldsymbol{R}_{\mathbf{4}}$ & $\boldsymbol{L}_{\mathbf{1 0}}$ & $\boldsymbol{L}_{\mathbf{1 1}}$ & $\boldsymbol{L}_{\mathbf{1 2}}$ & $\boldsymbol{L}_{\boldsymbol{z}}$ & $\boldsymbol{R}_{\mathbf{5}}$ \\
\hline value $(\mathbf{m m})$ & 0.130 & 0.130 & 1.050 & 16.180 & 0.580 & 0.830 & 2.580 & 0.780 & 1.590 \\
\hline
\end{tabular}

The gain and the reflection coefficient of dual-annular microstrip-fed antenna array of microstrip antenna array is shown in Figure 16. 
(a)

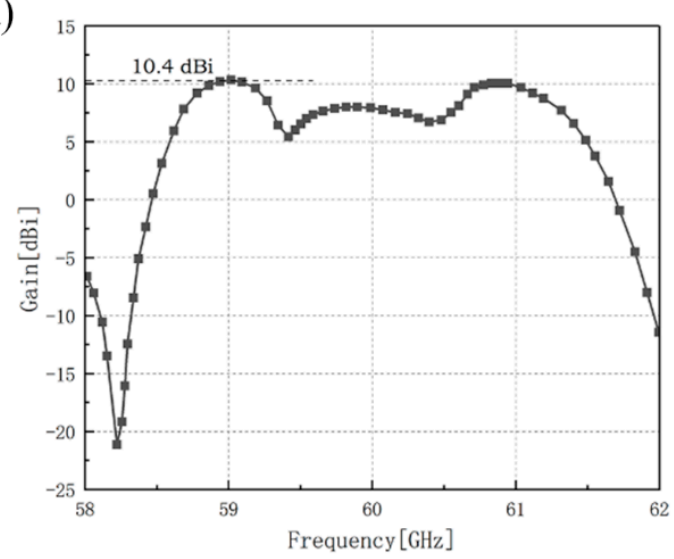

(b)

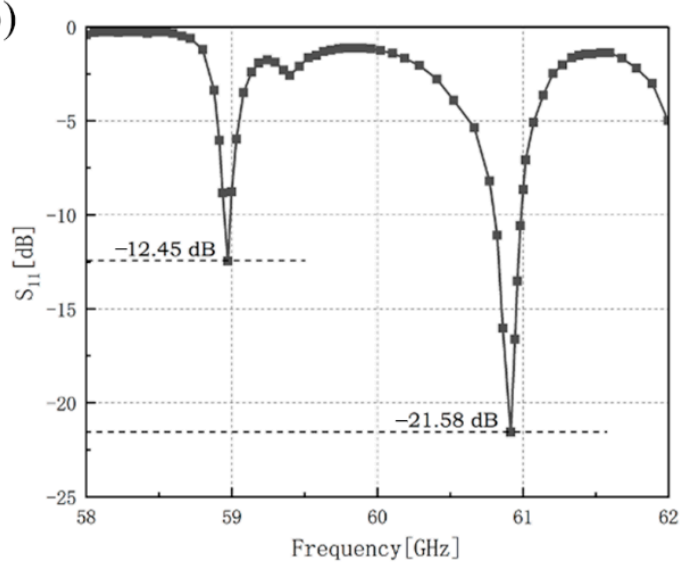

Figure 16. Simulation results of dual-annular microstrip-fed antenna array, (a) gain of this antenna array, (b) reflection coefficient of this antenna array.

The results show that the maximum gain of dual-annular microstrip-fed antenna array of microstrip antenna array is $10.4 \mathrm{dBi}$ at $59.0 \mathrm{GHz}$. In the frequency band of $59.0 \mathrm{GHz}-61.0 \mathrm{GHz}$, this antenna can remain a relatively high gain. Besides, the minimum reflection coefficient of it is $-21.58 \mathrm{~dB}$ at $60.9 \mathrm{GHz}$ and the reflection coefficient near the frequency of $58.97 \mathrm{GHz}$ can also attain below $-10 \mathrm{~dB}$.

For further confirmation, we depict the $x-z$ plane, $y-z$ plane, and $x-y$ plane of the radiation pattern of dual-annular microstrip-fed antenna array in Figure 17.

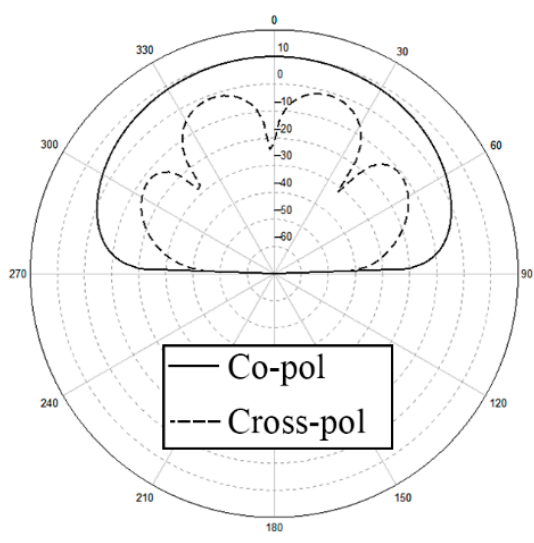

(a)

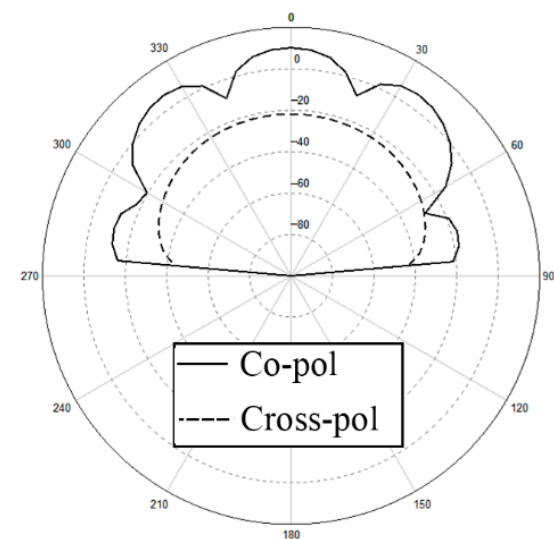

(b)

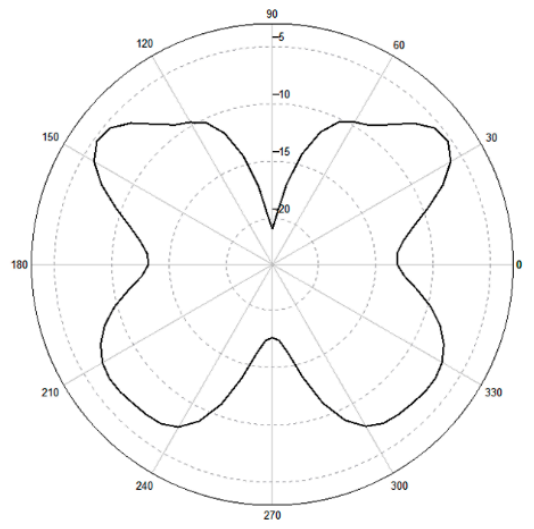

(c)

Figure 17. Radiation pattern of dual-annular microstrip-fed antenna array (a) $x-z$ plane, (b) $y-z$ plane, (c) $x-y$ plane.

\subsection{Bridged Annular-Microstrip-Fed Antenna Array}

This structure is shown in Figure 18. This design based on a bridged annular microstrip feeding line for the same four directional linear arrays with $1 \times 3$ rectangular patches as above structure. It proposes another solution for acquiring the characteristics of more uniform multi-directional radiation. The difference from the above three structures is that this structure uses central feeding mode. In addition to the outer microstrip line, this structure also contains mutually perpendicular straight internal microstrip lines with the same quantity as the array branches. One end of each internal microstrip line is connected to the ring midpoint of the connection point between the adjacent array unit and the outer ring microstrip line and the other end is at the center of overall structure. The internal microstrip lines are designed to match the central feeding mode which means each internal microstrip line should also implement the input impedance of $200 \Omega$. The length of each internal microstrip line should also be the integral multiple of the half-wavelength of the central frequency. With the central feeding mode, the structure has a high symmetry. 
(a)

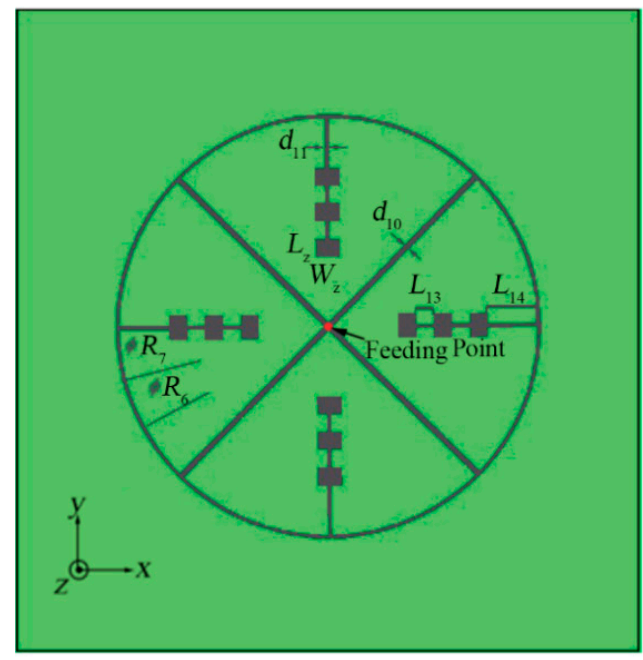

(b)

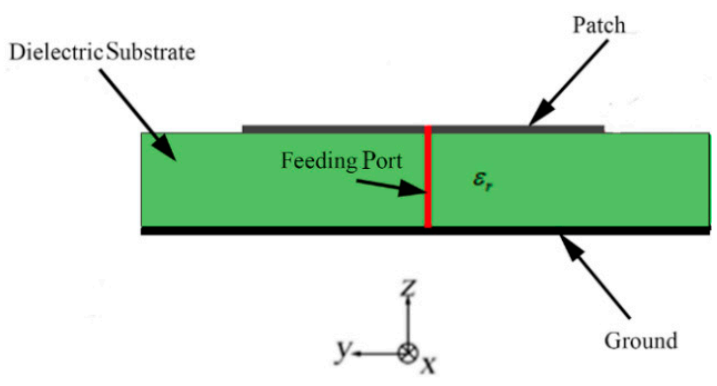

Figure 18. Bridged annular-microstrip-fed antenna array, (a), top view, (b), side view.

In order to gain a better simulation result, we set all the patches, microstrip line, and the mental ground of bottom layer as copper with the thickness of $0.006 \mathrm{~mm}$ which are different from the above three structures. However, the structure and material of the dielectric substrate are the same.

Because of the difference of the feeding mode, some structural parameters will have a relatively larger adjustment. The values of the parameters are shown in Table 4 . The meanings of the parameters are shown in Figure 18.

Table 4. Parameters of bridged annular-microstrip-fed antenna array.

\begin{tabular}{cccc}
\hline Parameter & Value $(\mathbf{m m})$ & Parameter & Value (mm) \\
\hline$R_{7}$ & 19.21 & $W_{z}$ & 1.050 \\
$R_{6}$ & 18.95 & $L_{z}$ & 0.780 \\
$d_{10}$ & 0.226 & $L_{13}$ & 0.830 \\
$d_{11}$ & 0.130 & $L_{14}$ & 2.580 \\
\hline
\end{tabular}

The gain and the reflection coefficient of bridged annular-microstrip-fed antenna array is shown in Figure 19.

(a)

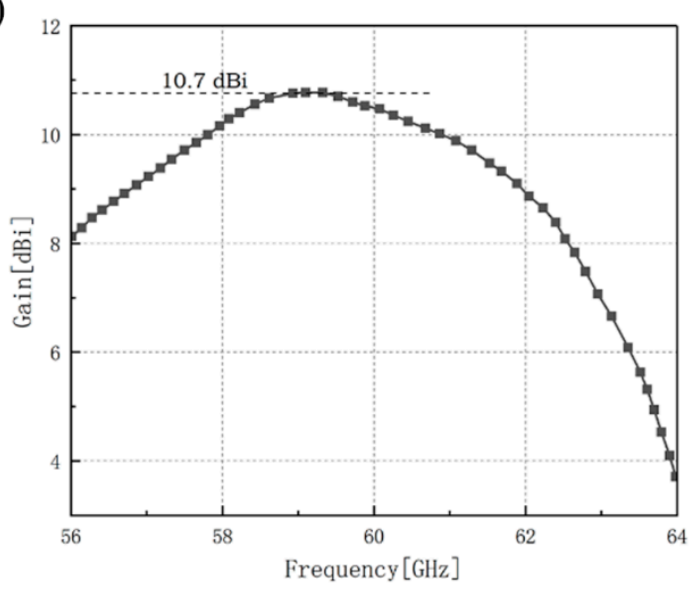

(b)

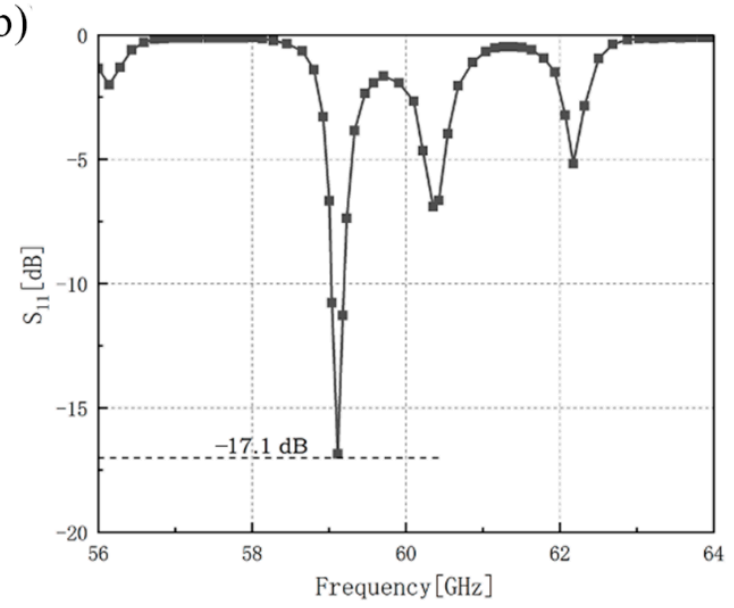

Figure 19. Simulation results of bridged annular-microstrip-fed antenna array, (a) gain of this antenna array, (b) reflection coefficient of this antenna array. 
The maximum gain of bridged annular-microstrip-fed antenna array of microstrip antenna array is $10.7 \mathrm{dBi}$ at $59.0 \mathrm{GHz}$ and the minimum reflection coefficient of it is $-17.1 \mathrm{~dB}$ at $59.1 \mathrm{GHz}$. Our designs reach a good impedance matching.

We depict the $x-z$ plane, $y-z$ plane, and $x-y$ plane of the radiation pattern of bridged annular-microstrip-fed antenna array in Figure 18 . With relatively uniform multi-directional radiation $H$-plane patterns shown in Figures 17 and 20, the latter two designs are multidirectional radiation antennas and have wide radiation ranges which achieve our goal.

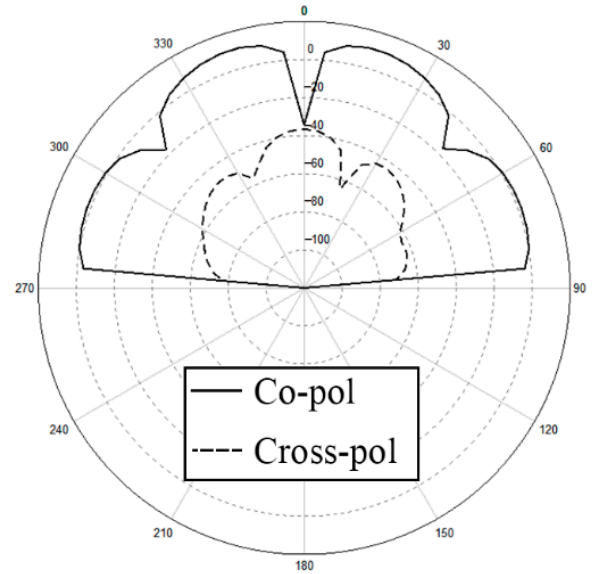

(a)

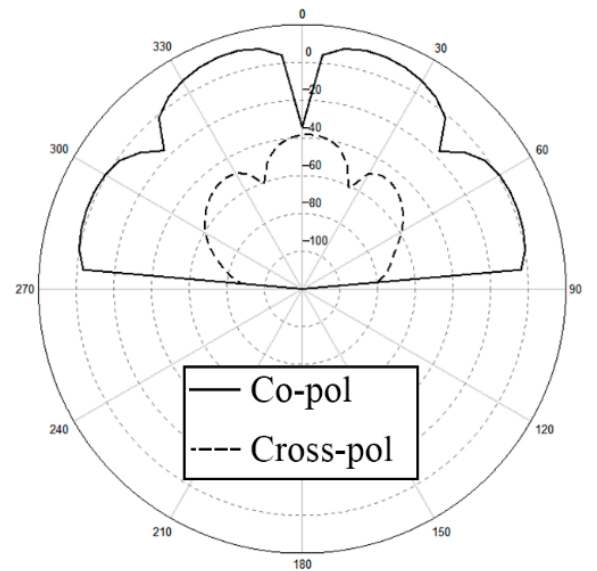

(b)

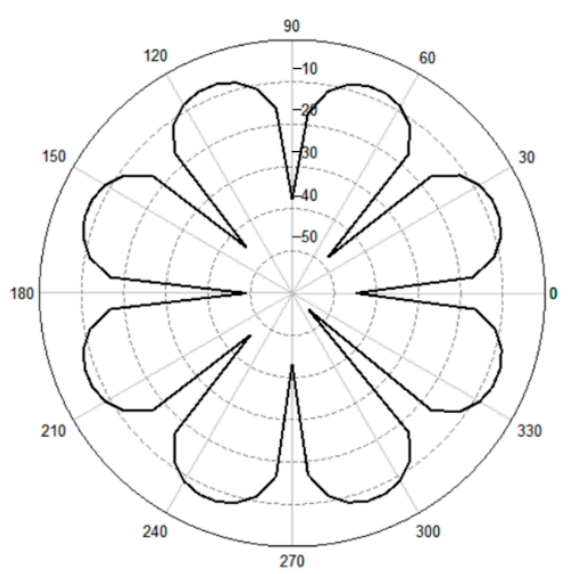

(c)

Figure 20. Radiation pattern of bridged annular-microstrip-fed antenna array (a) $x-z$ plane, (b) $y-z$ plane, (c) $x-y$ plane.

\section{Conclusions}

In this paper, aiming at the wider employment of the $\mathrm{mmW}$ frequency band in the future, we propose four novel structures of microstrip antenna array working at $60-\mathrm{GHz}$ waveband in total. Arrays are all composed of outer annular microstrip line and varying quantities and shapes of patch array branches. The quantity of the branches can be designed as $2 \sim 6$ at designer's option. All the feeding units are contained in the space inside the outer annular microstrip line, in order to obtain a more compact structure. The former two designs are the basic designs which show our design principle. The latter two designs are proposed to obtain the multi-directional radiation feature with the methods of dual annularmicrostrip feeding lines and central feeding mode. After simulating and optimizing, we finally achieve the goal of miniaturization of antenna and maintaining symmetrical highgain radiation in multiple directions under the condition of good impedance matching. Our study can make up for the deficiency of multi-direction characteristics in previous or current research on the mmW microstrip antenna array. In addition, we carried out the physical production and experimental verification of the first basic structure. We obtained the results of the minimum reflection coefficient of $-14.55 \mathrm{~dB}$ at $60.65 \mathrm{GHz}$ with the bandwidth of $540 \mathrm{MHz}$, which achieve a good match with the simulation results, so as to prove the correctness of our design. We anticipate that the design of this novel category of structures can provide potential guidelines for the future $\mathrm{mmW}$ coverage antenna design or practice.

Author Contributions: Conceptualization, S.P. and S.-D.L.; methodology, S.P.; software, C.W. and S.-D.L.; validation, S.P.; formal analysis: S.-D.L.; investigation, S.-D.L.; resources, S.-D.L., S.P. and C.W.; data curation: S.-D.L. and H.-Y.R.; writing—original draft preparation, S.-D.L.; writing—review and editing, S.P. and H.-Y.R.; visualization, S.-D.L.; supervision, S.P. and C.W.; project administration, S.P. All authors have read and agreed to the published version of the manuscript.

Funding: This research was supported in part by the Electrostatic Research Foundation of Liu Shanghe Academicians and Experts Workstation, Beijing Orient Institute of Measurement and Test (611704011), Hubei Key Laboratory of Roadway Bridge and Structure Engineering, Wuhan University of Technology (DQJJ201504), the Fundamental Research Funds for the Central Universities 
(191214001), and partly by the National Innovation \& Entrepreneurship Training Program for College Students (202010497046).

Data Availability Statement: Not applicable.

Acknowledgments: The authors thank the reviewers and editors for their careful works and thoughtful suggestions that help us improve this paper substantially, the assistance in measurement with Open Laboratory of Rohde \& Schwarz China, Shanghai Branch from the Fei Xun, and also in memory of the late Xiao-Ying $\mathrm{Xu}$ for her funding support.

Conflicts of Interest: The authors declare no conflict of interest.

\section{References}

1. Hong, T.; Zheng, S.L.; Liu, R.K.; Zhao, W.T. Design of mmWave Directional Antenna for Enhanced 5G Broadcasting Coverage. Sensors 2021, 21, 746. [CrossRef] [PubMed]

2. Naqvi, S.I.; Hussain, N.; Iqbal, A.; Rahman, M.; Forsat, M.; Mirjavadi, S.S.; Amin, Y. Integrated LTE and Millimeter-Wave 5G MIMO Antenna System for 4G/5G Wireless Terminals. Sensors 2020, 20, 3926. [CrossRef]

3. Dixit, A.S.; Kumar, S.; Urooj, S.; Malibari, A. A Highly Compact Antipodal Vivaldi Antenna Array for 5G Millimeter Wave Applications. Sensors 2021, 21, 2360. [CrossRef]

4. Kim, Y.J.; Kim, Y.B.; Lee, H.L. mmWave High Gain Planar H-Shaped Shorted Ring Antenna Array. Sensors 2020, $20,5168$. [CrossRef] [PubMed]

5. Gaya, A.; Jamaluddin, M.H.; Ali, I.; Althuwayb, A.A. Circular Patch Fed Rectangular Dielectric Resonator Antenna with High Gain and High Efficiency for Millimeter Wave 5G Small Cell Applications. Sensors 2021, 21, 2694. [CrossRef]

6. Song, C.T.; Pan, L.Z.; Jiao, Y.H.; Jia, J.G. A High-Performance Transmitarray Antenna with Thin Metasurface for 5G Communication Based on PSO (Particle Swarm Optimization). Sensors 2020, 20, 4460. [CrossRef]

7. Nakajima, M.; Sudo, K.; Fujii, H.; Kobayashi, E.; Hiratsuka, T. A wideband 60GHz chip antenna. In Proceedings of the 2012 Asia Pacific Microwave Conference Proceedings, Kaohsiung, Taiwan, 4-7 December 2012; pp. 328-330.

8. Bereka, D.; Gopinath, A.; Sainati, B. Design of a 60GHz integrated antenna on silicon substrate. In Proceedings of the 2014 IEEE Antennas and Propagation Society International Symposium (APSURSI), Memphis, TN, USA, 6-11 July 2014; pp. $1063-1064$.

9. Zhang, Y.P.; Sun, M.; Guo, L.H. On-chip antennas for 60-GHz radios in silicon technology. IEEE Trans. Electron Devices 2005, 52, 1664-1668. [CrossRef]

10. Razavi, S.A.; Kildal, P.S.; Xiang, L.L.; Alos, E.A.; Chen, H.G. $2 \times 2-$ Slot Element for 60-GHz Planar Array Antenna Realized on Two Doubled-Sided PCBs Using SIW Cavity and EBG-Type Soft Surface fed by Microstrip-Ridge Gap Waveguide. IEEE Trans. Antennas Propag. 2014, 62, 4564-4573. [CrossRef]

11. Shad, S.; Mehrpouyan, H. Electr. A compact and high gain dielectric-loaded 60GHz multi-stepped waveguide antenna array. Eng. Syst. Sci. 2019, 2, 1413-1414.

12. Delkhah, S.A.; Abdipour, A.; Mohammadi, A. Design of optimum grid antenna in $60 \mathrm{GHz}$ frequency band. In Proceedings of the 2012 Second Conference on Millimeter-Wave and Terahertz Technologies (MMWaTT), Tehran, Iran, 24-26 December 2012; pp. 21-24.

13. Zhang, S.; Zhang, Y.P. Analysis and synthesis of millimeter-wave microstrip grid-array antennas. IEEE Antennas Propag. Mag. 2011, 53, 42-55. [CrossRef]

14. Hayashi, Y.; Sakakibara, K.; Nanjo, M.; Sugawa, S.; Kikuma, N.; Hirayama, H. Millimeter-wave microstrip comb-line antenna using reflection-canceling slit structure. IEEE Trans. Antennas Propag. 2011, 59, 398-406. [CrossRef]

15. Rabbani, M.S.; Hooshang, G.S. Dual-layer partially reflective surface antennas based on extended size unit cells for $60 \mathrm{GHz}$ band WLAN/WPAN. IET Microw. Antennas Propag. 2018, 12, 789-795.

16. Zhang, Q.; Zhu, H.; Li, X.P. 60GHz high gain antenna based on loading AMC. Environ. Technol. 2014, z2, 30-32.

17. Tang, M.C.; Xiao, S.Q.; Guan, J.; Bai, Y.Y.; Gao, S.S.; Wang, B.Z. Composite metamaterial enabled excellent performance of microstrip antenna array. Chin. Phys. B 2010, 19, 074214.

18. Wang, H.F.; Wang, Z.B.; Cheng, Y.; Zhang, Y.R. Dual-polarized lens antenna based on multimode metasurfaces. Chin. Phys. B 2018, 27, 118401. [CrossRef]

19. Pu, S.; Guo, Q.Q.; Wang, H.R.; Xu, X.Y.C.N. A circumferential and uniform radiation mmW microstrip array antenna. Patent 107453054A, 8 December 2017.

20. Wang, H.R.; Pu, S.; Guo, Q.Q.; Xu, X.Y.C.N. Circumferential and vertically four-direction radiation mmW microstrip array antenna. Patent 206922021U, 23 January 2018.

21. Pu, S.; Wang, H.S.; Liu, Z.R.; Xu, X.Y.C.N. mmW microstrip antenna based-on annular feeding line. Patent 204680753U, 30 September 2015.

22. Zhang, G.; Pu, S.; Liu, Z.R.; Liu, W.F. Design of 60 GHz Microstrip Antenna Array Composed through Annular Feeding Line. In Proceedings of the 2016 IEEE International Symposium on Antennas and Propagation (APSURSI), Fajardo, PR, USA, 26 June-1 July 2016; pp. 1649-1650. 
23. Zhang, G.; Pu, S.; Xu, X.Y.; Liu, Y.; Wang, C. Design of 60-GHz Microstrip Antenna Array Composed through Circular Contour Feeding Line. In Proceedings of the 2016 Asia-Pacific International Symposium on Electromagnetic Compatibility (APEMC), Shenzhen, China, 17-21 May 2016; pp. 1010-1013.

24. WANG, Y.D.; Zhang, L.J.; Liu, F.H.; Zhao, Q.M.J.H. Comparison of performance characteristics of different shapes in microstrip patch antenna. J. Hebei Univ. Technol. 2017, 46, 1-5.

25. Sajin, G.; Craciunoiu, F.; Dinescu, A.; Mocanu, I.A. 48 GHz zeroth order resonance metamaterial antenna on alumina substrate. In Proceedings of the 2012 16th IEEE Mediterranean Electrotechnical Conference, Yasmine Hammamet, Tunisia, 25-28 March 2012; pp. $46-49$. 